\title{
A ANGÚSTIA DA INFLUÊNCIA NAS ARTES VISUAIS, COMO NA LITERATURA, COM HAROLD BLOOM
}

\section{Maria do Céu Diel Oliveira Escola de Belas Artes}

\section{Resumo}

Estes escritos buscam entender a possibilidade de migrar as categorias poéticas elencadas por Harold Bloom na Angustia da Influência ${ }^{1}$ - clinamen, tessera, kenosis, demonização, askesis e apófrades para as artes visuais como forma de entendimento, compreensão e superação da influencia poética/ artística. Assim, acredito que as mesmas categorias de Bloom para a literatura podem ser escopo de processo criativo nas artes visuais.

\section{Palavras-chave:}

Bloom, Angústia da Influência, artes visuais, poesia.

\section{Clinamen}

Escreveu Harold Bloom,

..." os poetas fortes fazem a história lendose mal uns aos outros, de modo a desobstruir um espaço de imaginação para si próprios. " (Bloom, 1991, p.17)

O que poderíamos entender na expressão ler-se ma? Escrevendo sobre teoria da poesia, Bloom propõe a existência do poeta forte e de todos aqueles que seguem sob sua égide. Apresenta então as formas como a poesia e seus criadores geram um generoso numero de seguidores e de como estes - conscientes desta influência - buscam a seus espaços de criação, ou nas palavras de Bloom, um desvio (idem, p.57). A influência angustiante é semelhante ao inferno na existência da arte. Arrastado pela irresistível presença do poeta forte, do artista dominante, em um círculo de outros poetas igualmente poderosos, resta ao artista ler mal: ler/ ver/ouvir o poeta de forma a permitir cacofonias, ruídos, manchas, brechas ou outras formas de infiltração de matéria poética, de substâncias contaminadoras de sua própria vida até então. Não se trata de uma forma de rejeição, de negar
Abstract

These writings seek to understand the possibility of migrating the poetic categories listed by Harold Bloom in Anguish Influence - clinamen, Tessera, kenosis, demonization, askesis and apofrades - for the visual arts as a way of understanding, understanding and overcoming the poetic / artistic influence. Thus, I believe that the same categories of Bloom for literature can be creative process scope of the visual arts.

Keywords:

Bloom, influence anguish, visual arts, poetry.

a dívida com o poeta forte, mas de entendimento da sobrevivência de ambos na memória de quem está vivo e criando. Percebo, portanto, que certos artistas se aproximam de outros cuidadosamente, num embate que ondeia entre o arrebatamento e a razão. Desta luta frutificam as camadas de construção de entendimentos, num ondejamento de adesão e descolamento. Aproximar-se, afastar-se, mergulhar, friccionar-se na obra do artista forte são movimentos que produzem ferimentos e cicatrizes, que preparam a pele de seu corpo criativo para outras provações. Fortalecidos na troca imaginal, os artistas admiradores de artistas fortes tornam-se também fortalezas, emanando em suas imagens/ textos/vozes direções e sentidos para onde outros seguirão, tateando, dedilhando, escarificando sua própria pele para nela perceber outros organismos, outras imagens corporificadas, fragmentos do artista forte. Escolha estética como escolha política, os artistas fortes que lêem/vêem/ouvem outros fortes enxergam-nos astigmaticamente para poderem sobreviver e encontrar-se mais tarde, transformados, desviados. 
Proponho então a migração desta teoria poética para as artes visuais, na medida em que uma leitura desfocada de um artista por outro pode produzir uma alucinação de entendimento, uma crítica e uma curva em direção a outras imagens.

Lemos em Bloom:

"Kierkegaard, em Temor e Tremor anuncia, com uma confiança magnífica, mas absurdamente apocalíptica que' aquele que está disposto a trabalhar, dá a luz ao seu próprio pai"' Continua, ao definir angústia segundo Freud: "A angústia antes de alguma coisa é claramente um modo de expectativa, como o desejo. (...) A angústia da influência é uma angústia quanto à expectativa de ser inundado. " Mas anuncia também o perigo pois:

" $E$, no entanto, esta metonímia dificilmente pode evitar-se: todo o bom leitor deseja literalmente afogar-se, mas se o poeta se afoga, tornar-se-á apenas um leitor." ${ }^{3}$

Ainda pensando segundo Freud, que reconheceu que "a sublimação era a conquista humana mais elevada" - sublimação esta caracterizada pelo abandono de modos de prazer mais primordiais a favor de modos mais refinados de prazer, significando exaltar a segunda oportunidade em relação a primeira. 0 sonho abandonado desta realização não é apenas uma fantasia de gratificação interminável, mas antes a maior de todas as ilusões humanas, o sonho da imortalidade.

Geoffrey Hartman ${ }^{4}$ distingue claramente entre prioridade - enquanto conceito da ordem natural - e autoridade, enquanto ordem espiritual. Portanto "ao tentar ultrapassar a prioridade (...) a arte combate a natureza no terreno desta e está destinada a perder". Assim os autores fortes estão condenados, por assim dizer, por esta não sabedoria. Uma empresa auto frustrata, nos dizer de Bloom, não o de "Prometeu, mas do Édipo Cego, que não sabia que a Esfinge era sua Musa." ${ }^{5}$ Batalhas entre iguais fortes, pais e filhos poéticos, Laio e Édipo, o eu poético aboriginal.

Podemos especular que os artistas de todas as épocas contribuíram para uma grande tela em progresso perpétuo. Borges observou que os poetas criam seus percursores. Para este estudo, admitiremos que os poetas/artistas fortes só leem a si próprios. Apontamos uma alegoria de um poeta/artista aido, o Satã de John Milton ${ }^{6}$, o arquétipo do poeta moderno. Bloom explicita que "o Satã se torna fraco quando raciocina e compara". O Paraíso Perdido é então a alegoria do dilema do poeta moderno. Segue a alegoria de Bloom, onde

"Satã é o poeta moderno, enquanto Deus é seu antepassado morto, ou melhor, o poeta ancestral, ainda embaraçosamente poderoso e presente. Adão é o poeta moderno potencialmente forte, embora em seu momento mais fraco, quando ainda não encontra sua própria voz. Deus não tem Musa, e não precisa dela, visto que está morto, manifestandose sua criatividade apenas no passado do poema."

Para acumular estas tantas imagens em tantos anos de vida, é vital que elas se cubram de poeira ou ricocheteiem entre paisagens e construções memoriosas ou que aspirem ao invés de respirarem para que o artista/contemplador possa sobreviver a elas. Assim Bloom lê em Lucrécio:

"Quando os átomos viajam para baixo, movidos pelo seu próprio peso, através do espaço vazio, em movimentos e lugares indeterminados desviam-se ligeiramente do seu curso, apenas o bastante para podermos considerar que houve uma mudança de direção. Não fora este desvio, tudo cairia verticalmente como pingos de chuva através do abismo do espaço. Nenhuma colisão teria lugar e não ocorreria nenhum impacto entre átomos. Assim nunca a natureza teria criado coisa alguma...

Mas o fato da mente não ter ela própria nenhuma necessidade de determinar cada um dos seus atos e forçá-los a sofrer uma passividade impotente deve-se ao ligeiro desvio dos átomos em momentos e lugares determinados." (Bloom, 91, pag 56).

Clinâmen é uma palavra latina que significa "inclinação". Foi o nome usado por Lucrécio para designar a espontânea curvatura dos átomos em uma trajetória vertical enquanto caem. Esta curva, este movimento é um movimento corretivo no próprio poema ou imagem.

Novamente o desvio na queda em direção à imagem forte, desta feita na forma infinitamente pequena da constituição da matéria da existência. Quando evocadas as imagens vividas ou sentidas, é forçoso percebê-las infinitamente fragmentadas, girandoas e acreditando tê-las compreendido, ou melhor, entendê-las da forma como elas também poderiam ser vistas. Então, em cada uma destas imagens de influência haverá uma partícula desviada, incompreendida, renegada, torta. Como folículos de uma pele marcada pelo tempo, onde convivem 
sinais da juventude desviados pelo presente do tempo, estas imagens tornam-se suportáveis e familiares, conformando o artista de sua existência e convívio com elas.

Escreve Malraux - o coração de qualquer jovem é um cemitério no qual se inscrevem os nomes de mil artistas mortos, mas cujos únicos residentes são uns poucos fantasmas poderosos e frequentemente antagonísticos. O poeta é assombrado por uma voz com a qual a palavra tem que se harmonizar. Malraux chega a fórmula - do pastiche ao estilo - que não é adequada a influência poética, pois o movimento de autorrealização encontra-se mais próximo do espírito mais drástico da máxima de Kierkegaard: aquele que está disposto a trabalhar dá a luz a seu próprio pai. Desde Homero que a influência poética é descrita como uma relação filial, mas no lluminismo demonstra-se um produto do dualismo cartesiano.

A palavra "influência" recebeu seu significado de "ter um poder sobre outra pessoa" logo no latim escolástico de São Tomás, mas durante séculos não perdeu seu sentido etimológico de "influxo", seu sentido primordial de uma emanação ou força sobre a humanidade proveniente dos astros. No seu primeiro uso, ser influenciado significava receber um fluxo etéreo proveniente dos astros, um fluido que afetava o caráter e o destino de uma pessoa. Porém a angústia precedeu seu uso. Por imitação, entende-se "ser capaz de converter a substancia ou as riquezas do outro poeta para nosso próprio uso. Fazer a escolha de um homem excelente sobre os demais, e assim segui-lo, até se tornar nele próprio, ou tão como ele como cópia que possa ser tomada por original."

Blake diz: ser escravizado pelo sistema de um percursor é ser inibido da criatividade por um raciocínio e uma comparação obsessivos, presumivelmente entre as próprias obras e as do percursor. Aí reside a natureza de perdas e ganhos da influência no labirinto da história. Blake distingue entre Estados e Indivíduos. Os indivíduos passam através de estados de ser e permaneciam indivíduos, mas os estados estavam sempre em movimento, sempre a oscilar. E só os estados eram culposos, os indivíduos nunca. A influência poética é uma passagem de indivíduos ou particulares através de estados.

Assim, o princípio geral do argumento é: A influência poética - quando diz respeito a dois poetas fortes, autênticos - processa-se sempre através de uma leitura má do poeta anterior, um ato de correção criativa que é realmente e necessariamente uma interpretação errônea. A história da influência poética frutífera, que o mesmo é dizer a tradição da poesia ocidental a partir do renascimento é uma história de angústia, e de caricaturas defensivas de distorções de revisionismos perversos e deliberados sem os quais a poesia moderna não poderia existir.

Mas o que é a influência poética? Pode o seu estudo ser mais do que a indústria enfadonha de caça as fontes, contagens de alusões?

O que dizer da máxima de Emerson: Insiste em ti: nunca imites. Como confrontar-se com o grande original?

O demônio da continuidade é o querubim protetor - ver no gênese os querubins que abriram suas asas para proteger a arca. Continuidade é gestão. Seu encanto pernicioso aprisiona o presente no passado e reduz um mundo de indiferenças a uniformidade acinzentada.

O poeta forte de fato diz: Parece que acabei de cair, agora sou caído e, portanto, aqui estou no Inferno, mas ao dizê-lo pensa: Ao cair, desviei-me portanto estou aqui num inferno melhorado pela minha própria criação?

\section{TESSERA, ou conclusão e antítese}

Bloom rememora o ensaio de Nietzsche Acerca da vantagem e da desvantagem da história para a vida, que leu como estudante em outubro de 1951:

"Podem-se criar as obras mais assombrosas; o enxame de eunucos históricos lá estará sempre no seu lugar, pronto a considerar o autor através de seus compridos telescópios. Ouve-se logo o eco, mas sempre sob a forma de 'crítica' apesar do crítico não sonhar com a possibilidade da obra um momento antes. Nunca chega a ter influência, mas só uma critica e a própria critica não tem influencia, mas gera outra critica. (...) O treino histórico de nossos críticos impedem que tenham qualquer influência no verdadeiro sentido do termo - uma influência sobre a vida e a a ação'B.

Continua a seguir dom a concepção de gênio, no seu Crepúsculo dos Ídolos:

"Os grandes homens, tais como as grandes épocas, são explosivos nos quais se armazena uma força 
terrível: a sua precondição, historicamente e psicologicamente é sempre que, durante muito tempo muito tenha sido coligido, armazenado, guardado e conservado para si - que não tenha havido uma explosão durante muito tempo. Quando a tensão desta massa se tornou demasiadamente grande, basta o estímulo mais acidental para convocar para este mundo o gênio, o ato, o grande destino. Não importam então o ambiente, a época, o espírito do tempo ou a opinião publica."

No nosso estudo sobre a migração da angústia da influência na poesia, poderemos então imaginar que buscamos no artista forte aquilo que amamos em nós, um espelho de si. Goethe escreve que amamos nos outros somente aquilo que lhes empresta, seus próprios eus, a sua versão de si. No mundo das imagens, é possível então que uma influência seja um fato previsível dentro de uma cadeia estética de promessas a nós mesmos como fazedores de imagens? Como Thomas Mann confessa enquanto escrevia o Dr. Faustus, escrevendo em seu diário: Sermos lembrados de que não estamos sozinhos no mundo - sempre desagradável. A imitiatio - ou a perseveração da virtude na vida de outro artista - é um modo de preservação e sobrevida das imagens. Bloom cita Mann, pois ilustra nosso 'século face aos desgostos da influência':

"Que papel o infantilismo - por outras palavras, a regressão a infância - esse elemento genuinamente psicanalítico, desempenha em nossas vidas! Que larga parte tem na formação da vida do ser humano; opera de fato exatamente do modo como descrevi: como identificação mítica, sobrevivência, percorrer das pegadas já existentes! O laço com o pai, a imitação do pai, o jogo de ser o pai e a transferência para figuras substitutas do pai de um tipo mais alto e mais elevado - como funcionam estes traços infantis na vida do indivíduo a marcam e a formam!(...) O artista em especial, um ser apaixonadamente infantil e lúdico, pode informarnos a respeito do efeito misterioso mas afinal óbvio de uma tal imitação infantil sobre sua própria vida, a sua condução produtiva de uma carreira que afinal não é se não a reanimação do herói só condições pessoais e temporais muito pessoais e com meios muito infantis, muito diferentes(...)."

O esquecimento é propriedade de toda ação. A ironia funciona para o artista como uma forma de negação da influência, pois, 'acreditar que chegamos tarde ao mundo é de qualquer modo nocivo e degradante; mas deve parecer assustador e devastador quando diviniza quem chegou tarde, mediante um golpe claro de leme através do qual o verdadeiro significado e o verdadeiro objetivo de toda a criação passada e de todo infortúnio consciente daquele, é disposto como a perfeição da história universal', como protesta Nietzsche.

Voltando a máxima de Kierkegaard sobre 'aquele que estiver disposto a trabalhar dará à luz a seu próprio pai' porém segundo Nietzsche 'quando não temos um bom pai é preciso inventar um'. Quando o artista - aqui, os criadores de imagens, sofre sua encarnação como artista, sente realmente angústia em relação a qualquer perigo que possa acabar com ele como artista. Daí a melancolia, a angústia da influência.

Quintus Curtius Rufus - historiador romano - evoca então as musas tocantemente para auxiliar o poeta a suportar sua memória do futuro:

'Aos poetas chamou-se propriamente de divinos, no sentido de adivinhos, divinari, adivinhar ou predizer. Sua ciência chama-se Musa, definida por Homero como o conhecimento do bem e do mal, isto é, adivinhação... Foi então a Musa a ciência de adivinhar através de auspícios... Urania, cujo nome vem de ouranos, céu, significa aquela que contempla o céu, para deles retirar os auspícios... e outras musas eram filhas de Júpiter - pois da religião nascem todas as artes da humanidade, das quais Apolo, tido principalmente por Deus da adivinhação, é a divindade principal - e cantam, no sentido em que os verbos latinos camere e cantare significam predizer.' O artista engendra de maneira freudiana a possibilidade de ser pai de si próprio, uma profecia e sabedorias sinistras.

Como perseguição de uma influência artística, avançaremos então para a tessera ou vínculo. Na tessera o artista posterior fornece aquilo que sua imaginação Ihe diz que vai completar sua obra. 0 termo tessera vem da observação de Mallarmé que "compara o uso corrente da Linguagem a circulação de uma moeda cujas faces só mostram efígies apagadas e que as pessoas passam de mão em mão, em silêncio." A função da tessera é como uma senha de reconhecimento. A tessera era empregada em religiões de mistério primitivas em que o reajustamento de duas metades de uma peça partida de cerâmica era usado como meio de reconhecimento por iniciados. 


\section{KENOSIS}

A terceira categoria de revisão poética é a Kenosis, ou "esvaziamento" como elenca Bloom, "um movimento da imaginação, de dissolução e isolamento". O termo é retirado da descrição de São Paulo, da "humilhação" de Cristo que de Deus se fez homem. Nos poetas fortes - e para nós aqui, os artistas fortes - a kenosis é um ato de revisão no qual tem lugar um esvaziamento ou um abaixamento em relação ao percursor. Bloom explica que tal esvaziamento é uma 'descontinuidade libertadora' e torna possível um tipo de poema que a simples repetição o afflatus ${ }^{10}$ não poderia permitir. Assim a dissolução do artista forte percursor em si próprio serve ainda para isolar o eu da posição de percursor. Serão, pergunta Bloom, estes mecanismos de defesa semelhantes aos que existem em nossa vida psíquica?

Porque a influencia - que poderia ser uma questão de saúde - é uma angústia? Acreditava-se numa pureza original, impossível de ser tocada pela mera experiência natural. Os artistas fortes devem crer nisto, visto que são, ao dizer de Bloom, "perversos" ${ }^{11}$. Desviar-se então pode ser etimologicamente entendido como 'limpar, limar, polir'. Porém a imaginação do poeta forte não se pode ver como perversa, sua inclinação tem que ser a saúde, a sua prioridade. Se o dom da imaginação provém necessariamente da perversidade do espírito, então 'o labirinto vivo da literatura constrói-se sobre as ruínas de nossos mais generosos impulsos'. Para as coisas e lugares indizíveis da imaginação, a potência da repetição perde-se. 'Não há nomes, diz Valery, para as coisas entre as quais o homem está mais verdadeiramente só'. A crítica aprecia a continuidade, mas aquele que vive da continuidade não pode ser um artista.

Bloom ironiza então o 'deus dos poetas não é Apolo, mas um gnomo careca chamado Ero, que vive nas traseiras de uma caverna (...) e que assoma de seu esconderijo apenas a intervalos regulares para festejar os poderosos mortos na escuridão da lua' (primos são Desvio e Conclusão). São adoradores da continuidade, pois só ali tem alcance. E conclui que 'só o leitor Ideal ou o Verdadeiramente Corrente gosta da descontinuidade e um tal leitor está ainda a espera de nascer ${ }^{12}$ (Hermes envelhece, transformase em Erro e inventa o comércio). As relações inter poéticas não são nem comércio nem roubo.
Bloom então apresenta a noite e a morte, amigas do poeta/artista forte. 'As folhas tornam-se gritos emudecidos e não se ouvem gritos reais'. As continuidades começam com a manhã, mas então nenhum poeta pode ceder a injunção de Nietzsche - tenta viver como se fosse manhã Enquanto poeta, o artista deve viver como se fosse meia noite - uma 'meia noite suspensa'. O lugar e o fato para o artista forte é a sensação de ter sido projetado de forma centrífuga e cadente, em direção ao mar. Instintivamente tenta manter-se na sua borda, mas o impulso antitético o empurra para o interior, para a demanda de fogo. A demanda de fogo é a descontinuidade. A repetição pertence a borda da água - QUE ONDE O ID, O PERCURSOR DO POEMA ESTÁ, FIQUE O MEU POEMA. Mas a repetição pode ser elevada dialeticamente a recriação, mesmo sendo, segundo Freud, uma pulsão de morte enquanto inércia, regressão, entropia. Assim na repetição temos o enunciado da pulsão regressiva, ou morte. Mas Kiergegaard enuncia que 'se o próprio Deus não tivesse querido a repetição o mundo nunca teria podido aceder a existência. Teria ou seguido os leves planos da esperança ou recordado tudo e tudo conservado em memória'. Mas tal não fez e por isso o mundo subsiste devido ao fato de que é uma repetição. A vida que passou torna-se agora. 0 único lugar onde pode o artista ser feliz é na repetição. Mas o poeta forte sobrevive porque vive na descontinuidade de uma repetição dissolvente e isolante. Quando o efebo pede a Musa que o ajude a lembrar do futuro é quase como se pedisse uma repetição. Condenação do percurso a queda em um chão bem duro.

\section{DEMONIZAÇÃO - ou contra-sublime}

O novo artista forte deve reconciliar em si próprio duas coisas - o ethos (identificação) é o daimon (espírito) e "Todas as coisas foram feitas através dele e nada que foi feito foi feito sem ele".

Para Bloom, os poemas emergem não como uma resposta a um tempo presente, mas em resposta a outros poemas. Para Rilke, 'os tempos são resistência'. Para Rilke, a história era o índice dos homens que nasceram cedo demais, mais a arte é o índice dos homens nascidos tarde demais.

Os antigos referiam-se a demônios queriam também referir-se àqueles que pela grandeza de alma também se aproximam dos deuses. Nascer de um íncubo celeste não é senão ter um espírito grande 
e poderoso, muito acima da fraqueza terrena dos homens. $O$ poder que faz do homem um artista é demonico, pois é um poder que distribui e divide - 0 sentido primitivo de daeomai - pois distribui nossos destinos e divide nossos dons, compensando-nos sempre daquilo que nos tira.

Tal divisão traz ordem, confere conhecimento, desordena onde conhece, abençoa com a ignorância para criar uma outra ordem.

Os demônios de Marsilio Ficino ${ }^{13}$ existiram para trazer as vozes dos planetas para homens protegidos. Tais demônios eram a influência, movendo-se de Saturno para o gênio, mais abaixo, transmitindo a mais generosa das melancolias. Em verdade, o poeta forte nunca é possuído por um demônio, mas é ele o demônio, ao menos que enfraqueça e se deixe possuir. Ao voltar-se contra o Sublime do percursor, o novo artista forte sofre uma demonização, um Contra Sublime, que sugere a relativa fraqueza do percursor. Enquanto o novo artista forte é demonizado, seu percursor é humanizado. O Sublime do poeta forte não é o Sublime do leitor a não ser que cada vida de cada leitor divida uma Alegoria. Assim o Sublime do Leitor é o de Burke, um agradável terror. Este leitor cede à simpatia e recusa a descrição, pois precisa ver 0 mais indefinido dos contornos. Na demonização, a consciência poética é ampliada e vê contornos nítidos e devolve a descrição o que tinha cedido a mais à simpatia.

Nesta categoria de revisão poética, o Grande Original permanece grande, mas perde sua originalidade, cedendo-a ao mundo no númen - poder dos espíritos ou deidades presentes nos lugares e nos objetos. Esta é uma guerra de orgulhos, mas a negação do percursor nunca é possível, já que nenhum novo artista forte pode permitir ceder a pulsão de morte, pois a literalidade poética visa a imortalidade literal, e todo poeta pode ser definido como um evitar de uma morte possível.

Como imagens de um movimento em direção a demonização, Bloom aponta uma queda para fora e para baixo, um voo, uma espécie de queda ascendente. Projetado pela glória inebriante de participar da glória do percursor, o artista parece levitar, numa experiência de afflatus que o abandona nas alturas, elevado a extravagância. A ajuda para sair desta extravagância é possível apenas se for uma ajuda exterior. Imagine-se então este artista forte fora do alcance da ajuda e que seria invariavelmente destruído por ela. Desta forma, o artista deve localizar 3 domínios: a paisagem, o eu interior, o olhar do outro. Assim, migrando estes movimentos humanos para os domínios do poema teremos o afastamento, solipsismo ${ }^{14}$ e olhar imaginado do percursor. Portanto, para se apropriar da paisagem do percursor o jovem artista precisa se afastar cada vez mais de si próprio. Para atingir um eu ainda mais interior que seu percursor, o artista torna-se cada vez mais solipsista. Para se furtar ao olhar imaginado de seu percursor, o artista coloca-o ao seu alcance, imaginando um olhar mágico que assiste a todos seus movimentos. 0 olhar desejado é amistoso ou apaixonado, mas o olhar temido é o de reprovação, o que torna o jovem artista forte indigno do amor mais elevado.

Ao mover-se por paisagens mudas, de coisas e lugares que the falam cada vez menos, o jovem artista reconhece também o custo de uma interioridade maior, da separação de tudo o que é extenso. Perde-se a reciprocidade em relação ao mundo, quando comparada com a reciprocidade que o percursor teve em relação ao mundo, a quem todas as coisas falavam.

Partindo da ideia freudiana de que a tradição 'equivale ao material recalcado na vida mental do indivíduo' então a demonização deve aumentar o recalcamento, colocando o percursor ainda mais na tradição que na sua corajosa individuação.

Muito daquilo que chamamos loucura ou o perigoso equilíbrio foi simplesmente o exercício desta perigosa defesa, a demonização. Será esta uma revisão uma ekstasis - este último passo para o além - apenas a intensidade da repressão da imaginação?

Como na visão de Abraão - 'quando o sol se pôs e se estenderam as trevas, eis que uma fogueira fumegante e uma tocha de fogo passaram entre os animais divididos... SOMBRA é bela a palavra de Deus que a ele não volta até que volte a fogueira'.

\section{Askesis ou purgação}

Bloom apresenta nesta quinta categoria a askesis - o ascetismo, ou a sublimação dos instintos pois afirma que 'a sublimação dos instintos de agressividade é central para a escrita e a leitura da poesia e é quase idêntica ao processo de encobrimento poético'. Assim a sublimação poética 
é uma askesis, um modo de purgação, que visa um estado de solidão'.

O poeta forte está então inebriado e consegue 'a um preço terrível' virar toda sua energia para si próprio e vê sua vitória contra os 'poderosos mortos'. De fato, apenas a sublimação pode nos dar uma espécie de 'pensamento liberto do nosso passado sexual' e modificar o impulso instintivo - ou criativo, no nosso caso - sem o destruir. Bloom explicita que os 'poetas em particular (...) são incapazes de existir quer numa frustração prolongada quer numa renúncia estóica'. E pergunta:

“...como podem eles receber o mais fundo prazer, o êxtase da prioridade, do auto-engendramento, de uma autonomia certa, se a sua vida para o Verdadeiro Sujeito e os seus próprios Verdadeiros Eus atravessam o sujeito do precursor e o seu eu? ".

O orfismo, religião natural de todos os poetas enquanto poetas, carrega, segundo Bloom 'uma infelicidade'. Os órficos, que adoram o Tempo como origens de todas as coisas reservavam sua verdadeira adoração para Dionisio, devorado pelos Titãs e renascido de Semele. A infelicidade deste mito está nas cinzas dos 'Titãs pecaminosos'. E continua dizendo que 'todo o êxtase poético, todo o sentimento de que o poeta sai do homem para deus, reduz este amargo mito, como o faz todo o ascetismo poético'.

O jovem artista transformado pela purgação da sua posição de revisão é descendente dos adeptos órficos. Sendo vitima da compulsão à repetição transportava "água com uma peneira para o Hades".

Se pensarmos numa 'filosofia da composição' é necessariamente uma genealogia da imaginação, um estudo da única 'culpa' que importa para o poeta, a culpa da dívida. Assim Bloom evoca Nietzsche quando este diz que 'não há talvez nada mais terrível na história remota de um homem que sua mnemotécnica', pois a intuição associava toda a criação de uma memória a uma dor atroz. Assim Bloom explica que todos os costumes são uma seqüência de processos de apropriação, inclusive as defesas e reações. Assim entendemos esta categoria poética como uma consciência da força do antepassado, promovido ao lugar de deus primitivo. Mas aquilo que os poetas chamam de purgatório, pode ser denominado de sublimação. Esta sublimação pode ser chamada de 'elaboração'. Quando elaboramos tornamo-nos ao mesmo tempo Prometeu e Narciso. Mas para esta contemplação deve fazer um sacrifício, pois 'na medida em toda a criação-por-evasão depende de um sacrifício'. Citando Cornford ${ }^{15}$, Bloom explicita que a humanidade 'aparece' em Hesíodo quando 'Prometeu rouba de seus a melhor parte' e ainda no Gênesis 'o primeiro pecado cometido pela expulsão de nossos primeiros pais do paraíso foi motivado pelos sacrifícios oferecidos por Abel e Caim'. Assim, a escrita e a leitura de poemas são um processo sacrificial, uma 'purgação que esgota mais do que restaura'. Cada poema - ou obra artística no nosso caso - é uma invasão não se de outro poema, mas também de si próprio. Para poder separar a alma do corpo é necessária uma 'internalização', não só um afastamento da alma em relação a si própria mas também de todos os precursores e seus mundos. 'Deformado em cima, deformado para cima' como escreve Bloom, o poeta não pode permitir uma outra kenosis. A askesis 'enquanto defesa eficaz contra a angústia da influência' age como uma espécie de cegueira em relação as outras realidades e exterioridades, até emergir um novo estilo de rudeza, 'com vários graus de solipsismo'. Assim, Bloom explica que na sua askesis purgatorial o poeta só conhece a si próprio e ao outro, seu precursor que finalmente 'deve destruir e que a esta altura pode ser uma figura imaginária, mas ainda formada por poemas passados que não se deixarão esquecer'.

De fato, continua Bloom, 'o clinamem e a tessera tentam corrigir e completar os mortos, a kenosis e a demonização trabalham no sentido de recalcar a memória dos mortos, mas a askesis é a verdadeira 'luta de morte contra os mortos'. E então Bloom nos faz recordar de Dante e seu mestre Virgilio. Quando depois de longa peregrinação e com o desaparecimento de Virgilio para ser substituído por Beatriz, após as inúmeras barreiras e conversas no Inferno, finalmente o poeta é nomeado, quando Beatriz o chama "Dante!".

\section{Apófrades, ou o regresso dos mortos}

Bloom inicia esta categoria citando Empédocles que 'acreditava que nossa psique ao morrer retornava ao fogo de onde tinha vindo'. Mas não o nosso demônio, que nos foi herdado. A genealogia da imaginação traça uma descendência do demônio e 'a obra de um poeta forte pode expiar a obra de um precursor'. Os mortos fortes 
podem 'regressar' quer nos poemas quer em nossas vidas. O poeta forte é vulnerável a esta ultima fase na sua relação de revisão com os mortos. Os apófrades - os dias desoladores e infaustos em que os mortos regressavam para habitar suas antigas casas - acontecem para os poetas fortes, como um 'influxo'. Toda a tirania do tempo é derrubada e pode-se acreditar que 'os poetas fortes estão a ser imitados pelos seus antepassados'. Para discutir esta categoria, Bloom evoca Borges, segundo o qual os artistas 'criam seus precursores'. "Assim, de maneira 'drástica' o poeta forte coloca na sua própria obra o antepassado de forma que 'as passagens concretas da obra deste se pareçam não como presságios de nosso próprio advento, mas serão diminuídas pelo nosso próprio resplendor." Os poderosos mortos regressam, mas regressam nas nossas cores e falam as nossas vozes e (...) testemunham a nossa persistência e não a sua'. Desta forma, Bloom afirma que o deleite do ego maduro 'se reduz ao mistério do narcisismo, aquilo que Freud chama primário e normal - o complemento libidinal do egoísmo do instinto de auto-preservação'. O amor do artista forte por sua arte tem que excluir a realidade de toda a arte restante. Assim os apófrades, quando 'geridos por uma imaginação capaz do poeta forte que persistiu na sua força', tornam-se não apenas o regresso dos mortos, mas uma celebração do regresso, da exaltação de si anterior que tornara antes possível a poesia'.

Bloom evoca Artaud a conclamar que: "Deixem os poetas mortos abrirem o caminho a outros. Poderemos então compreender que é a nossa veneração pelo que já está criado que nos petrifica". É mais importante que os novos artistas/poetas possuam um conhecimento rico. Os precursores inundam-nos, mas nossas imaginações não podem se afogar neles.

\section{Notas}

1. Bloom, H. A Angustia da Influencia, uma teoria da poesia. Ed. Cotovia, Portugal, 1991.

\section{Bloom, ibidem pág 70}

3. Ainda aqui sobre uma teoria da poesia, que desejo transpor para uma teoria da angústia nas artes, inundando-me da possibilidade desta angustia míope.
4. In Bloom, pág 21

5. Bloom, pág 22

6. Lost Paradise, 1667.

7. Bloom, pag 57

8. Bloom, pag, 63

9. Bloom, pag 64

10. Termo latino derivado de Cícero em De natura Deorum, que significa inspiração, ser insuflado pelos deuses.

11. Bloom pag 98. Perverso, no sentido literal, 'virado para o caminho errado'.

\section{Bloom, pág 92}

13. Ficino, médico e astrólogo do século XV (14331499), buscou a síntese entre o pensamento aristotélico e o neoplatonismo cristão. Essa síntese foi colocada a serviço da Astrologia e da Medicina. O propósito expresso de seus esforços era mostrar, ao homem saturnino, alguma possibilidade de escapar dos perigos de seu temperamento e patrono celestial e desfrutar de seus benefícios. Mas sua obra vai muito além de sua intenção original. O sistema desenvolvido por Ficino foi absolutamente revolucionário para o pensamento médico e científico: sem ele, jamais teria surgido o pensamento de Paracelso. Para Ficino, a alma possuía três faculdades distintas que formavam um todo hierarquicamente ordenado: a imaginação (imaginatio), a razão discursiva (ratio), e a razão intuitiva (mens). Só as faculdades inferiores do homem estavam, até certo ponto, sujeitas a influência dos astros; as faculdades da alma, em particular a "mens", eram essencialmente livres.

A influência das forças cósmicas tem que se haver com a consciência individual, o problema astrológico é a questão vital da vontade humana, consciente ou inconsciente: é a questão da eleição ética. 0 humano, ser ativo e pensante, é fundamentalmente livre e pode, inclusive, governar a força dos astros, expondo-se de maneira consciente e voluntária à sua influência. Para tanto, ele propõe uma autoterapia astrológica, uma reordenação deliberada de sua própria razão e imaginação. Essa é a "Magia Natural" de Ficino. 
A obra de Ficino acaba culminando em uma glorificação de Saturno, o Deus-Ancião que renunciou ao mando em troca da sabedoria e trocou a vida no Olimpo por uma existência dividida entre a mais alta esfera do céu e as profundidades mais interiores da Terra.

Shakespeare, Cervantes, Michelângelo, são alguns exemplos dessa melancolia conscientemente cultivada. Pois a síntese mais perfeita para a inteligência se atinge quando o verdadeiro humor se acerca da melancolia, ou quando a verdadeira melancolia se transfigura pela ação do humor.

14. Solipsismo (do latim "solu-, «só» +ipse, «mesmo»+-ismo".) é a concepção filosófica de que, além de nós, só existem as nossas experiências. O solipsismo é a consequência extrema de se acreditar que o conhecimento deve estar fundado em estados de experiência interiores e pessoais, não se conseguindo estabelecer uma relação direta entre esses estados e o conhecimento objetivo de algo para além deles. $O$ "solipsismo do momento presente" estende este ceticismo aos nossos próprios estados passados, de tal modo que tudo o que resta é o eu presente.

15. CORNFORD, F. M. Principium Sapientiae: as origens do pensamento filosófico grego. Trad. Maria Manuela Rocheta dos Santos. 3. ed. Lisboa: Fundação Calouste Gulbenkian, 1989. Resenha de João Mattar

\section{BIBLIOGRAFIA:}

Bloom, Harold: Abaixo as verdades sagradas. Companhia de Bolso, São Paulo,2012.

: The Anatomy of the Influence-

Literature as a Way of Life. Yale University Press, Londres, 2011.

\section{: A Angustia da Influência: uma}

teoria da Poesia. Edições Cotovia, Lisboa, 1991.

Bolzoni, Lina: Il cuore di Cristallo- Ragionamento d'amore, poesia e ritratto nel Rinascimento. Giulio Einaudi Editore, Torino, 2011.

Brook, Peter: 0 espaço vazio. Ed. Orfeu Negro, 2011, Lisboa.

Celant, Germano: Anselm Kiefer- II sale della
Terra. Skira ,2011, Milano.

Cornford. F.M: Principium Sapientiae: As origens do Pensamento Filosófico Grego. Editora Fundação Calouste Gulbenkian, Lisboa, 1989.

Forster, Kurt M., Mazzucco, Katia: Introduzione ad Aby Warburg e all Atlante della Memoria, Bruno Mondadori, Milano, 2002.

Muhana, Adma: Poesia e Pintura ou Pintura e Poesia- Tratado Seiscentista de Manuel Pires de Almeida. FAPESP/EdUSP, São Paulo, 2002.

Oliveira, Maria do Céu Diel: Conversações com imagens in Diálogos com a Arte, Revista de Arte, Cultura e Educação, volume 1, 2010, pags 9 a 22, Braga.

Pepiatt, Michael: Em El taller de Giacometti, 2010, Barcelona.

Vircondelet, Alan: Balthus - Memorias . Editorial Lumen S.A, Barcelona 2002.

Yates, Frances A: The Theatre of the World. Barnes and Noble, New York, 2009.

\section{FILMOGRAFIA:}

Over your cities Grass Will grow- Sophie FiennesGermany, 2010.

\section{SOBRE A AUTORA}

Maria do Céu Diel de Oliveira. Professora Associada do Departamento de Desenho da Escola de Belas Artes. Doutora em Educação pela Universidade Estadual de Campinas (2000).

E-mail: mariadiel@gmail.com 